\title{
El procedimiento de inscripción registral a través de la gamificación en un escenario de docencia virtual
}

\author{
Jesús Palomares Bravo
}

Contratado Predoctoral Plan Propio de Investigación y Transferencia, área de Derecho Civil, Universidad de Málaga

jpbravo@uma.es

\section{Resumen}

En un contexto de docencia virtual a causa de la pandemia generada por la COVID-19, las universidades han tenido que emprender una transformación significativa de cara a la implementación efectiva de recursos educativos digitales.

Dentro de la carga docente del área de derecho civil, en el caso de la Universidad de Málaga, la disciplina halla asiento fuera de la propia Facultad de Derecho, con asignaturas en otros centros y facultades cuyos planes de estudios incorporan asignaturas introductorias en las que se estudian elementos del derecho civil patrimonial. Los programas de dichas asignaturas incorporan al final un tema dedicado al Registro de la Propiedad como órgano encargado de publicitar la titularidad de los derechos reales que recaen sobre bienes inmuebles. El desarrollo de esta experiencia de innovación docente pretende acercar la realidad registral práctica al alumnado.

Siguiendo esta premisa, con el ánimo de captar la atención y entusiasmo participativo de los estudiantes, se usa la técnica de la gamificación a través de la herramienta virtual Kahoot aplicada al procedimiento registral, de forma que contribuya al aprendizaje de realidades jurídicas de gran utilidad práctica en la vida extraacadémica.

El planteamiento no parte únicamente de una explicación técnica y teórica del funcionamiento del Registro de la Propiedad a través de los principios registrales y procedimientos articulados en la Ley Hipotecaria y su Reglamento como textos normativos de referencia. Tratamos mostrarlo con documentos reales que contengan actos y negocios jurídicos, permitiendo al alumno seguir de una forma más dinámica y efectiva el procedimiento de forma simplificada. Ello ha contribuido a despertar su interés y conciencia ante una institución que les resulta ab initio apática. 
Las situaciones jurídicas para el caso propuesto han sido la presentación de una escritura pública de compraventa a los efectos de efectuar un cambio de titularidad dominical en el Registro de la Propiedad, además de verificar la inscripción de un derecho real de garantía a través de la inscripción de un contrato de préstamo con garantía hipotecaria sobre la vivienda adquirida.

A los efectos de verificar la operatividad del procedimiento registral, se distribuye la sesión en dos partes; La primera de carácter descriptivo-expositivo exhibe en primer término, los documentos a inscribir, y la situación inicial de las fincas registrales mediante notas simples explicando el contenido de las mismas (titularidades, cargas). Seguidamente, se exhibe el asiento de presentación, y el documento de calificación registral expedido por el Registrador de la Propiedad competente, en el que realiza una calificación positiva de la legalidad de los documentos presentados, procediendo a la modificación de los folios registrales. Finalmente, se exhibe el folio registral a través de una nota simple con las modificaciones efectuadas, comparándose con la situación inicial. De esta forma verifica el alumno de forma sencilla y simplificada, la efectividad de la dinámica registral.

Concluida la parte descriptiva-expositiva, pasamos a la fase gamificativa, en la que en síntesis se plantean cuestiones relacionadas con el procedimiento y los documentos registrales exhibidos, a través de 10 cuestiones con 4 posibles respuestas. Para su acceso, se facilita el enlace a la herramienta Kahoot a través del chat de la herramienta Blackboard Collaborate empleada para las sesiones teóricas virtuales síncronas. 